パルスレーザー堆積法により低温成膜した $\mathrm{Al}-\mathrm{Zn}-\mathrm{O}$ 系透明導電膜*

安倉 秀明*1 · 高瀬 康則*1 . 中村 篤宏*1 . 東村 佳則*1

鈴木 晶雄*1・青木 孝憲*1・松下 辰彦*1 $\cdot$ 奥田 昌宏*2

\title{
Transparent Conducting Al-Zn-O Films Prepared at Low Temperature by Pulsed Laser Deposition
}

\author{
Hideaki AGURA*1, Yasunori TAKASE*1, Atsuhiro NAKAMURA*1, Yoshinori HIGASHIMURA*1, \\ Akio SUZUKI*1, Takanori AOKI*1, Tatsuhiko MATSUSHITA*1 and Masahiro OKUDA*2 \\ *1Department of Electronics, Information and Communication Engineering, Osaka Sangyo University, \\ 3-1-1 Nakagaito, Daito, Osaka 574-8530, Japan \\ *2Okuda Technical Office, 1-2-27 Mozu-Umemachi, Sakai, Osaka, 591-8032, Japan
}

(Received May 11, 2006 Accepted July 1, 2006)

\begin{abstract}
50 465-nm-thick Al-doped zinc oxide (AZO: $1.5 \mathrm{wt} . \% \mathrm{Al}_{2} \mathrm{O}_{3}$ ) films have been prepared on glass substrates at low temperature by pulsed laser deposition (PLD) using ArF excimer laser and Nd:YAG laser. During the deposition process, oxygen with partial pressure of $0-1.6 \mathrm{~Pa}$ was introduced in the chamber. As a result, with oxygen partial pressure of $0.5 \mathrm{~Pa}$, an excellent optical transmittance in the visible wavelength range was obtained for 50 to 465 -nm-thick AZO films and the lowest resistivity of $3.16 \times 10^{-4} \Omega \cdot \mathrm{cm}$ was obtained for approximately 405-nm-thick AZO film. FE-SEM and AFM observations revealed that for 50-nm-thick AZO film, some fine particles like the crystal-embryo were recognized on the surfaces. With increased film thickness, the value of surface roughness increased because of large grain size.
\end{abstract}

\section{1. はじめに}

近年, 社会の情報化が急速に進みディスプレイの分野で は，現行の地上アナログ放送が2011年 7 月に停波予定であ ることから，それに合わせて地上デジタルチューナー内蔵の プラズマディスプレイ（PDP）及び液晶ディスプレイ (LCD) の需要が急増している. また, 次世代ディスプレイ として有望視されている有機エレクトロルミネッセンス (EL) ディスプレイの開発も進んでいる. 現在, これらのデ ィスプレイ用透明導電膜として実用化されている材料のほと んどが ITO (インジウムスズ酸化物) 透明導電膜1-2)である が，これに含まれるインジウムは諸般の事情で生産量が減少 し, さらに消費量の急激な増加により枯渴する恐れがある. そこで最近, 資源が豊富 (埋蔵量でインジウムの約 10 万倍) な酸化亜鉛を用いた透明導電膜が注目されている.

我々は以前よりこの酸化亜鉛に注目し，高品質な薄膜を得 ることが出来るパルスレーザー堆積 (PLD) 法にて透明導 電膜の作製に関する報告を行ってきた ${ }^{3-6)}$. 現在市販されて いるフラットディスプレイのほとんどがガラス基板を用いて いるが，これがプラスチックなどの基板に置き換える事が出 来ればディスプレイの軽量化やコスト低下に繋がる.しかし ながら, 良好な透明導電膜の作製には通常, 高温での熱処理 過程が必要であるためプラスチックなどの基板に置き換える ためには作製温度の低温化技術の確立が必須である.

そこで今回, 著者らはレーザー光源に ArF エキシマレー

\footnotetext{
$*$ 平成 17 年 11 月 10 日 第 46 回真空に関する連合講演会で講演 $(10 \mathrm{P}-8,10 \mathrm{P}-9)$

*1 大阪産業大学工学部電子情報通信工学科（干574-8530 大阪府 大東市中垣内 3-1-1)

*2 奥田技術事務所（厂591-8032 大阪府堺市百舌鳥梅町 1-2-27）
}

ザー（ $\lambda=193 \mathrm{~nm} ）$ およびエキシマレーザーでは不可欠のガ ス交換作業が不要でメンテナンス性に優れた Nd:YAGレー ザーの第 4 高調波 $(\lambda=266 \mathrm{~nm})$ を用いたパルスレーザー堆 積法で, $\mathrm{AZO}$ ( $\mathrm{Al}$ を添加した酸化亜鉛）透明導電膜を基板 温度室温 $\sim 200^{\circ} \mathrm{C}$ の低温（一般的な透明導電膜は $300^{\circ} \mathrm{C}$ 以上 の高温にて作製）として作製した. その結果，レーザー波長 の違いにより大きな変化が現れたので報告する.

\section{2. 実験方法}

成膜は Table 1 の条件で行った。AZO透明導電膜は Corning\#7059 ガラス基板に成膜し, 基板温度は室温（約25 $\left.{ }^{\circ} \mathrm{C}\right)$ とした．実験には $\mathrm{ArF}$ エキシマレーザー（ $(\lambda=193 \mathrm{~nm})$ および Nd:YAGレーザーの第 4 高調波 $(\lambda=266 \mathrm{~nm})$ を用 いた.ターゲットは $\mathrm{ZnO}$ に $\mathrm{Al}_{2} \mathrm{O}_{3}$ を 1.5 wt.\%添加した純度 99.99\%の50 mm $\phi \times 5 \mathrm{~mm}$ 厚の焼結体を用い, レーザービー ムが一個所に集中しないように約 4 r.p.m. で回転させて成膜 を行った．その他の成膜条件は Table 1 に示す通りである.

膜の評価は, 膜厚測定には段差式膜厚計, 抵抗率などの電 気的特性には van der Pauw 法を用いたホール効果測定装 置, 透過率などの光学的特性には自記分光光度計を用いて行 った. また表面・断面観察は電界放出型走査電子顕微鏡（以 下 FE-SEM) および原子間力顕微鏡 (以下 AFM), 結晶構 造分析は X 線回折 (以下 XRD) で行った.

\section{3. 実験結果及び考察}

Fig. 1 に Table 1 の条件下で, チャンバー内の酸素分圧 を $0 \sim 1.6 \mathrm{~Pa}$ と変化させて成膜を行った場合の電気的特性を 示す．この図より, $\mathrm{ArF}$ エキシマレーザーの場合は酸素分 圧が $0.3 \sim 0.5 \mathrm{~Pa}$ の時に抵抗率が減少し, 抵抗率 $\rho$ は $6.53 \times$ $10^{-4} \Omega \cdot \mathrm{cm}$ （移動度 $\mu=11.6 \mathrm{~cm}^{2} / \mathrm{V} \cdot \mathrm{s}$, キャリア密度 $n=$ 
Table 1 Preparation conditions

\begin{tabular}{|c|c|c|}
\hline \multirow{3}{*}{$\begin{array}{c}\text { Laser } \\
\text { Nd:YAG Laser } \\
(\lambda=266 \mathrm{~nm}) \text { or } \\
\text { ArF Excimer Laser } \\
(\lambda=193 \mathrm{~nm})\end{array}$} & Laser Energy & $\begin{array}{c}50 \mathrm{~mJ} \text { (Nd:YAG Laser) } \\
60 \mathrm{~mJ} \text { (ArF Excimer Laser) }\end{array}$ \\
\hline & Repetition Frequency & $10 \mathrm{~Hz}$ \\
\hline & Laser Energy Density & $\begin{array}{c}1.0 \mathrm{~J} / \mathrm{cm}^{2} \text { (Nd:YAG Laser) } \\
1.2 \mathrm{~J} / \mathrm{cm}^{2} \text { (ArF Excimer Laser) }\end{array}$ \\
\hline \multirow{7}{*}{ Chamber } & Target & AZO (1.5 wt. $\left.\% \mathrm{Al}_{2} \mathrm{O}_{3}\right)$ \\
\hline & Substrate & Corning $\# 7059$ \\
\hline & Target to Substrate Distance & $\begin{array}{c}60 \mathrm{~mm}(\mathrm{Nd}: \mathrm{YAG} \text { Laser }) \\
40 \mathrm{~mm} \text { (ArF Excimer Laser) }\end{array}$ \\
\hline & Substrate Temperature & Room Temperature \\
\hline & Base Pressure & $5.0 \times 10^{-4} \mathrm{~Pa}$ \\
\hline & Gas Pressure & $0 \sim 1.6 \mathrm{~Pa}\left(\mathrm{O}_{2}\right)$ \\
\hline & Film Thickness & $50 \sim 465 \mathrm{~nm}$ \\
\hline
\end{tabular}

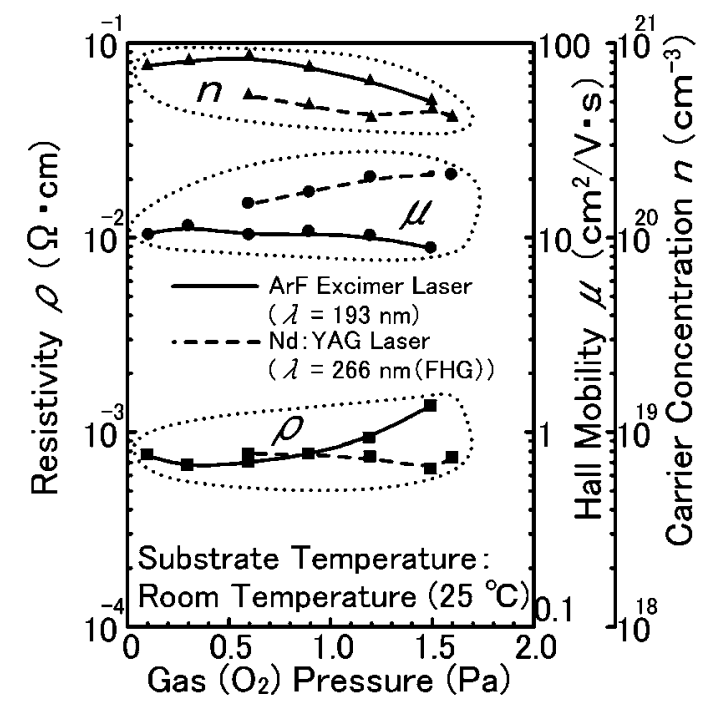

Fig. 1 Electrical properties of the AZO films grown by various gas pressure $\left(\mathrm{O}_{2}\right)$.

$\left.8.26 \times 10^{20} \mathrm{~cm}^{-3}\right), \mathrm{Nd}: \mathrm{YAG} レ$ レ゙ーの場合は酸素分圧が $1.5 \mathrm{~Pa}$ の時，抵抗率 $\rho$ は $6.46 \times 10^{-4} \Omega \cdot \mathrm{cm}$ （移動度 $\mu=21.1$ $\mathrm{cm}^{2} / \mathrm{V} \cdot \mathrm{s}$ ，キャリア密度 $\left.n=4.58 \times 10^{20} \mathrm{~cm}^{-3}\right)$ であった。抵 抗率はほぼ同じ值が得られているが，レーザー波長の違いに より，移動度およびキャリア密度に大きな違いがあることが 確認できた.これは, レーザー光が長波長側にシフトするこ とで熱的なアブレーション過程（サーマルアブレーション過 程）の要素が増えるため, プルーム中の粒子の振る舞いに変 化が生じたためではないかと考えられる.

次に，Nd：YAGレーザーを用い，最小抵抗率が得られた 酸素分圧 $1.5 \mathrm{~Pa}$ にて成膜した透明導電膜を FE-SEM（10万 倍）抢よび $\mathrm{AFM}(1 \mu \mathrm{m} \times 1 \mu \mathrm{m})$ により観察した結果を Fig. 2 (a) に，基板を加熱して成膜した場合との違いを見る ために基板温度を $100^{\circ} \mathrm{C}$ およ゙ $200^{\circ} \mathrm{C}$ とした場合の観察結果 をそれぞれ Fig. 2(b)，Fig. 2(c)に示す.FE-SEM 像よ り, 基板温度が高いほど結晶粒径が小さく, 密に詰まった構

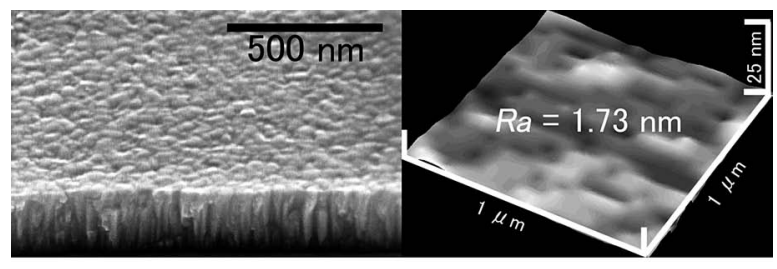

(a) Room Temperature $\left(25^{\circ} \mathrm{C}\right)$

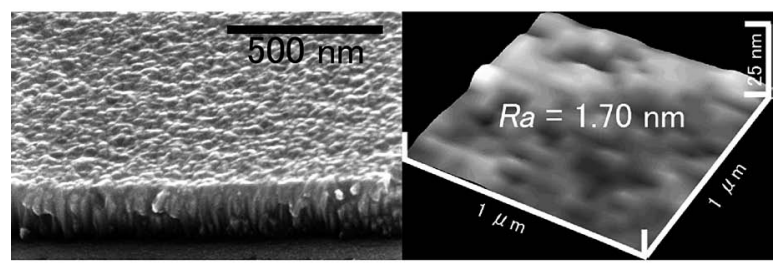

(b) $100^{\circ} \mathrm{C}$

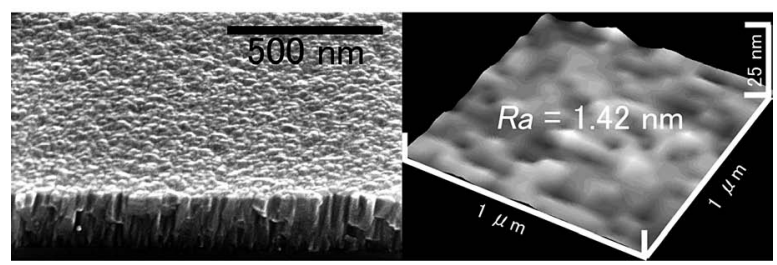

(c) $200^{\circ} \mathrm{C}$

Fig. 2 Surfaces of the AZO films fabricated by irradiating laser pulsed with various substrate temperature using $\mathrm{Nd}$ : YAG laser: (a) room temperature (about $25^{\circ} \mathrm{C}$ ), (b) $100^{\circ} \mathrm{C}$ and (c) $200^{\circ} \mathrm{C}$.

造となっていることが確認できた．これは，基板を加熱して 成膜することで膜の稠密化が促進されたためである. AFM による分析より, 表面平均粗さ $R a$ の值は基板温度が室温の 時に $R a=1.73 \mathrm{~nm}, 100^{\circ} \mathrm{C}$ の時 $R a=1.70 \mathrm{~nm}, 200^{\circ} \mathrm{C}$ の時 $R a=$ $1.42 \mathrm{~nm}$ であった。 これは, 基板温度が室温の場合は一つ一 つの結晶粒径が大きいことから $R a$ の值が僅かながら大きく なり, 基板温度が $100^{\circ} \mathrm{C}, 200^{\circ} \mathrm{C}$ の場合は一つ一つの結晶粒 径が小さく稠密構造となっていることから $R a$ の值が小さく 


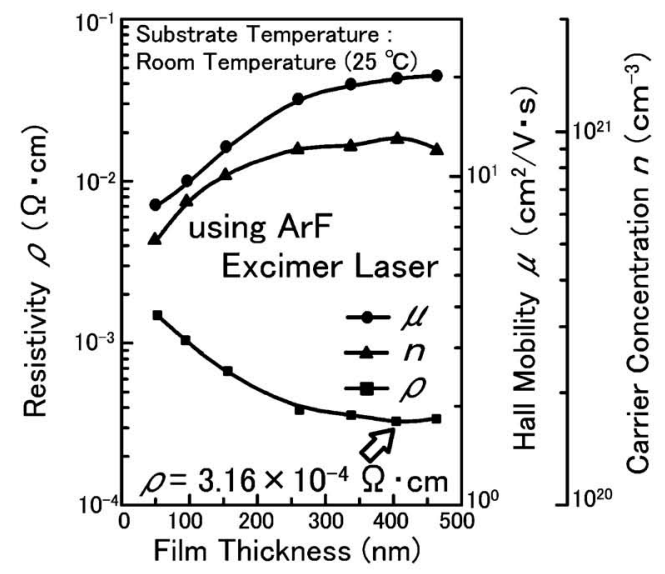

(a)

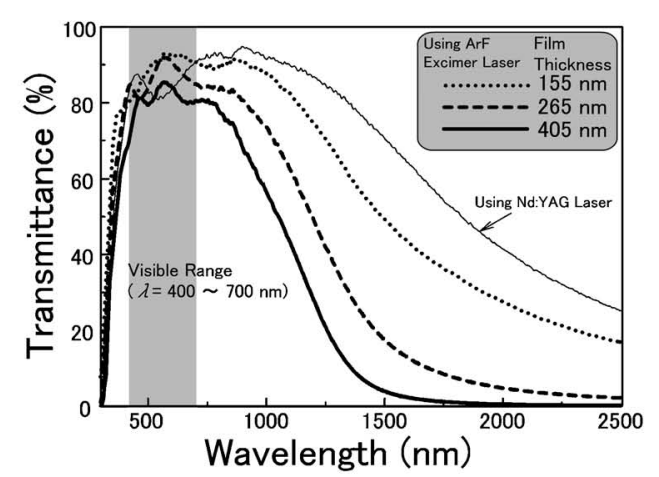

(b)

Fig. 3 Film thickness dependence of (a) electrical properties and (b) optical transmittance spectra of the AZO films using ArF excimer laser.

なったと思われる。

Fig. 3(a)に ArF エキシマレーザーを用い，膜厚を変化さ せて成膜を行った場合の電気的特性を示す。この図より膜厚 が $405 \mathrm{~nm}$ の時, 最も抵抗率が減少し, 抵抗率 $\rho$ は $3.16 \times$ $10^{-4} \Omega \cdot \mathrm{cm}$ （移動度 $\mu=19.9 \mathrm{~cm}^{2} / \mathrm{V} \cdot \mathrm{s}$, キャリア密度 $n=$ $\left.9.95 \times 10^{20} \mathrm{~cm}^{-3}\right)$ であった.これらの薄膜および $\mathrm{Nd}: \mathrm{YAG}$ レーザーにて最小抵抗率が得られた酸素分圧が $1.5 \mathrm{~Pa}$ の薄 膜を自記分光光度計により透過率スペクトルを測定した結果 を Fig. 3(b)に示す．この図より，いずれの膜も可視光領域 における平均透過率は $80 \%$ 以上を有し, 透明導電膜として 十分機能する值であった。 また，膜厚を増加させるにつれて 長波長側の透過率が減少しているが，これは膜中の自由電子 のプラズマ共鳴現象および膜厚の増加により透過率が減少し たためである.

Fig. 4 に膜厚を変化させて成膜したときの XRD パターン を示す．この図より，膜厚が $405 \mathrm{~nm}$ の時に最も $\mathrm{ZnO}(0002)$ 面の回折強度が大きく, 結晶性が良いことがわかる.この時 の $\mathrm{ZnO}(0002)$ 面の半值幅（FWHM）を求めたところ, $0.351^{\circ}$ と室温成膜としては良好な值であった，XRD 測定で は通常, 膜厚の増加に伴い回折強度が大きくなるが, 膜厚が $465 \mathrm{~nm}$ の場合は $405 \mathrm{~nm}$ と比べて回折強度が小さくなって いる. これは, 膜厚が $400 \mathrm{~nm}$ を超えると膜の成長過程で格 子の乱れが発生したためと思われる.

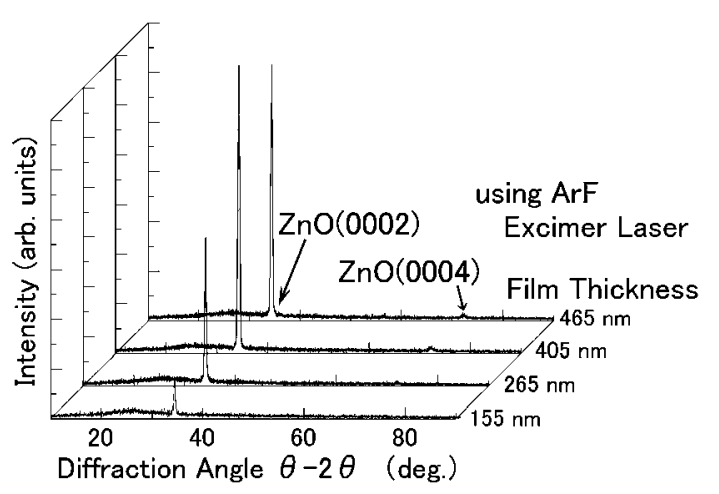

Fig. 4 XRD spectra of the AZO films prepared by laser deposition with various film thickness.

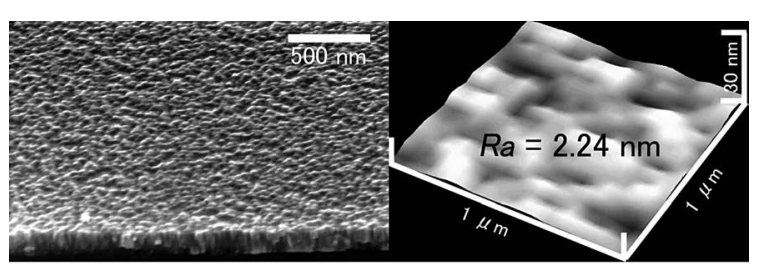

(a) $155 \mathrm{~nm}$

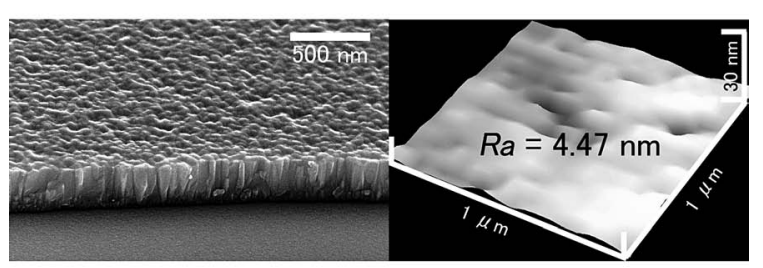

(b) $265 \mathrm{~nm}$

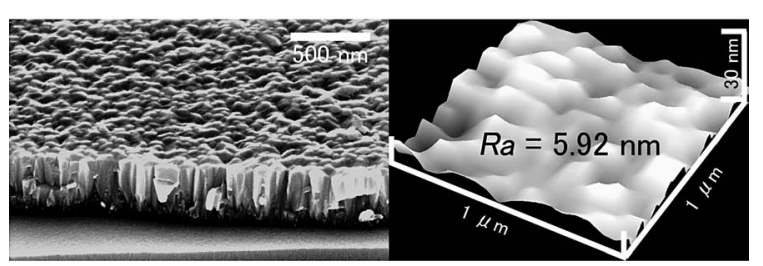

(c) $405 \mathrm{~nm}$

Fig. 5 High-resolution FE-SEM and AFM images of the AZO films fabricated by irradiating laser pulsed with various film thickness: (a) $265 \mathrm{~nm}$ (b) $405 \mathrm{~nm}$ and (c) $465 \mathrm{~nm}$.

次に，膜厚を(a) $155 \mathrm{nm,} \mathrm{(b)} 265 \mathrm{~nm}$ および(c) $405 \mathrm{~nm}$ と して成膜を行った薄膜の表面・断面を FE-SEM（5 万倍） で観察した結果抢よび表面平均粗さを AFM $(1 \mu \mathrm{m} \times 1 \mu \mathrm{m})$ により測定した結果を Fig. 5 に示す. FE-SEM 像より, 全 て断面に柱状結晶が確認できた。これは，Fig. 4 の XRD パ ターンの面回折ピークとよく一致し, 基板に垂直に柱状の結 晶として，すなわち $\mathrm{c}$ 軸配向していることがわかる。 また， $\mathrm{AFM}$ により表面平均粗さ $R a$ を求めたところ, 膜厚が薄い 場合はアモルファス状の結晶構造となることで Raの值は小 さく, 膜厚を増加させると結晶成長が促進され個々の結晶粒 径が大きく成長したことで $R a$ の值は増加した. 以上の結果 より, 膜厚の違いにより膜の表面構造および結晶構造に大き な影響を与えることが分かった。 


\section{4. まとめ}

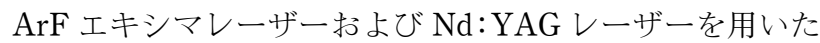
パルスレーザー堆積法で透明導電膜を作製し以下の結果を得 た。

1）基板温度を室温として成膜を行う場合，チャンバー 内に酸素を導入することで膜中の酸素空孔を減少させ，酸素 欠陥の適正化を図ることで, 抵抗率が減少した。

2）基板温度を室温（約 $\left.25^{\circ} \mathrm{C}\right) \cdot 100^{\circ} \mathrm{C} \cdot 200^{\circ} \mathrm{C}$ とした膜を FE-SEM およびAFM により分析を行った結果，基板温度 が高いほど結晶粒径が小さく, 密に詰まった構造となり表面 平均粗さ $R a$ の值も小さくなった.

3） XRDによる分析結果より，膜厚を厚くすると基板に 垂直に柱状結晶が成長した $\mathrm{c}$ 軸配向を示す $\mathrm{ZnO}(0002)$ 面の 回折ピークが大きくなり, 結晶化が促進されることがわかっ た.
4）膜厚を変化させることで電気的特性が顕著に変化 し, 膜厚 $405 \mathrm{~nm}$ で最小抵抗率 $\rho=3.16 \times 10^{-4} \Omega \cdot \mathrm{cm}$ （移動度 $\mu=19.9 \mathrm{~cm}^{2} / \mathrm{V} \cdot \mathrm{s}$ ，キャリア密度 $\left.n=9.95 \times 10^{20} \mathrm{~cm}^{-3}\right)$ の室 温成膜では良好な結果を得た。

\section{〔文献〕}

1) Hirokazu Izumi, Tsuguo Ishihara, Hideki Yoshioka and Muneyuki Motoyama: Thin Solid Films, Vol. 411, (2002) 32.

2) A. Suzuki, T.Matsushita, T. Aoki, A. Mori and M. Okuda: Thin Solid Films, Vol. 411, (2002) 23.

3）鈴木晶雄, 石田大顕, 振木昌成, 青木孝憲, 松下辰彦, 奥田昌 宏 : 真空，42巻 3 号 (1999) 321 .

4）鈴木晶雄, 谷 善之, 青木孝憲, 松下辰彦, 奥田昌宏 : 真空, 46巻 8 号 (2003) 632

5）安倉秀明, 沖中広和, 甫木茂靖, 青木孝憲, 鈴木晶雄, 松下辰 彦, 奥田昌宏：電気学会論文誌 C, 123巻, (2003) 1916.

6）甫木茂靖, 鈴木晶雄, 青木孝憲, 松下辰彦, 奥田昌宏 : 真空, 48 巻 3 号 (2005) 169 . 